\title{
TEORIA ATOR-REDE (TAR) COMO INSTRUMENTO DE PESQUISA EM TURISMO: BUSCANDO APROXIMAÇÕES E CONTRIBUIÇÕES
}

ACTOR-NETWORK THEORY (ANT) AS A RESEARCH TOOL FOR TOURISM: SEEKING APPROACHES AND CONTRIBUTIONS

\author{
TEORÍA ACTOR-RED (TAR) COMO INSTRUMENTO DE \\ INVESTIGACIÓN EN TURISMO: BUSCANDO APROXIMACIONES \\ Y CONTRIBUCIONES
}

\begin{abstract}
ANNA KARENINA CHAVES DELGADO
Mestre em Turismo pela Universidade Federal do Rio Grande do Norte -

UFRN, Natal, Rio Grande do Norte, Brasil

Professora do curso técnico em hospedagem do Instituto Federal de

Pernambuco - IFPE, Cabo de Santo Agostinho, Pernambuco, Brasil

anna.chaves@cabo.ifpe.edu.br

http://orcid.org/0000-0003-0806-7624
\end{abstract}

\section{JACKELINE AMANTINO DE ANDRADE}

Doutora em Administração pela Universidade Federal do Rio Grande do

Sul - UFRGS, Porto Alegre, Rio Grande do Sul, Brasil

Professora do Programa de Pós-Graduação em Administração da Universidade Federal de Pernambuco - UFPE, Recife, Pernambuco, Brasil

jackeline.amantino@gmail.com

http://orcid.org/0000-0002-6451-4049

Licença CC BY:

Artigo distribuído

sob os termos

Creative Commons,

permite uso

e distribuição

irrestrita em

qualquer meio

desde que o autor credite a fonte original.

DATA DE SUBMISSÃO: 25/04/2018 - DATA DE ACEITE:17/09/2018

RESUMO: O artigo apresenta as principais ideias da Teoria Ator-Rede (TAR) discutidas por seus fundadores e suas aplicações em pesquisas sobre turismo, visando despertar o interesse de pesquisadores brasileiros a respeito da temática, tendo em vista que a TAR tem o potencial de proporcionar novas formas de análise ao fenômeno turístico. Assim, para apresentar um breve panorama desses estudos, seleciona-se uma amostra de periódicos nacionais e internacionais por meio do CiteScore da Scopus e do estrato Qualis da CAPES, e dentro desses são feitas buscas nos títulos, resumos e palavras-chave pelas expressões Teoria Ator-Rede, translação, simetria generalizada e performatividade. A partir dessas buscas, é possível perceber que a quantidade de artigos internacionais é superior, assim como a variedade temática. As produções nos periódicos internacionais analisados não se encontram restritas a um grupo de autores específicos, no entanto, em termos geográficos, ainda estão associados a instituições europeias. Também se nota que a performatividade, tema mais frequente em periódicos internacionais, é associada a discussões sobre autenticidade, multiplicidade e processos de organização, enquanto que os artigos que se referem diretamente à TAR e à translação discutem especialmente a heterogeneidade do turismo. 
PALAVRAS-CHAVE: Teoria Ator-Rede. Análise Bibliométrica. Estudos Turísticos.

ABSTRACT: This article presents the main ideas of Bruno Latour, Michel Callon and John Law on ActorNetwork Theory (ANT), and their applications to tourism research. The aim of this article is to encourage Brazilian tourism researchers to study the subject, since ANT has the potential to provide new forms of analysis in tourism. Thus, to present a brief overview of these studies, a sample of national and international journals was selected using CiteScore by Scopus and Qualis stratum by CAPES. These databases were searched for titles, abstracts and keywords containing the search terms actor-network theory, translation, generalized symmetry and performativity. Based on these searches, it was perceived that there are more international articles on the subject, as well as thematic variety. The articles in the international journals analyzed are not restricted to a group of specific authors; however, in geographical terms, they are associated with European institutions. It is also noted that performativity, a more frequent topic in international journals, is associated with discussions about authenticity, multiplicity, and organizational processes, while articles that refer directly to ART and translation mostly discuss the heterogeneity of tourism.

KEY-WORDS: Actor-Network Theory. Bibliometric Analysis. Tourism Studies.

RESUMEN: El artículo presenta las principales ideas de la Teoría Actor-Red (TAR) discutidas por sus fundadores y sus aplicaciones en investigaciones sobre turismo, buscando despertar el interés de investigadores brasileños acerca de la temática, teniendo en vista que la TAR tiene el potencial de proporcionar nuevas formas de análisis al fenómeno turístico. Así, para presentar un breve panorama de estos estudios, se selecciona una muestra de periódicos nacionales e internacionales a través del CiteScore de la Scopus y del estrato Qualis de la CAPES, y dentro de ellos se buscan en los títulos, resúmenes y palabras clave por las expresiones Teoría Actor -Red, traslación, simetría generalizada y performatividad. A partir de estas búsquedas es posible percibir que la cantidad de artículos internacionales es superior, así como, la variedad temática. Las producciones en las revistas internacionales analizadas no se encuentran restringidas a un grupo de autores específicos, sin embargo, en términos geográficos, todavía están asociados a instituciones europeas. También se nota que la performatividad, tema más frecuente en periódicos internacionales está asociada a discusiones sobre autenticidad, multiplicidad y procesos de organización, mientras que los artículos que se refieren directamente a TAR y traslación discuten especialmente la heterogeneidad del turismo.

PALABRAS CLAVE: Teoría Actor-Red. Análisis Bibliométrico. Estudios Turísticos.

\section{INTRODUÇÃO}

A Teoria Ator-Rede (TAR), ou Actor-Network Theory (ANT), também denominada de sociologia das associações, consiste num aporte teórico-metodológico que foi desenvolvido por Bruno Latour, Michel Callon e John Law, da L'Ecole des Mines, visando, a princípio, contribuir para os estudos de ciência e tecnologia (Bijker, 1986). Essa acaba por se destacar ao propor a simetria entre humanos e aquilo que denomina como não humanos, sendo esse último entendido como objetos, animais, fenômenos da natureza, materiais, etc., ou seja, toda uma variedade de elementos que não sejam pessoas (Latour, 1994, 2012).

Quando os humanos se relacionam e interagem com os não humanos, acabam por formar associações e é por meio dessas que produzem os fenômenos sociais. Para a TAR, a sociedade nada mais é do que o resultado das muitas associações estabelecidas entre humanos e não humanos (Callon, 1986; Latour, 2012). Dessa maneira, o que importa é estudar as ações relacionais que levam à formação das associações ou das composições 
entre elementos heterogêneos (humanos e não humanos). Para descortinar os fenômenos sociais, deve-se voltar o olhar para as ações de associação, assim cabe ao cientista social seguir os atores para identificar as associações que eles estabelecem (Callon, 1986; Law, 1992). Essa é a metodologia desenvolvida pela TAR, seguir as ações dos humanos e não humanos, também chamados de actantes, que leva a formação das associações.

Por meio desse processo torna-se possível, por exemplo, entender como o conhecimento científico é formado dentro de um laboratório na Califórnia (Latour \& Woolgar, 1997), ou mesmo observar a constituição das técnicas de navegação a longa distância em busca de uma nova rota para a Índia (Law, 1986). Ainda se pode estudar a associação que leva à formação de um mercado de morangos no interior da França (Callon, 1998) e assim por diante, vários são os exemplos de aplicação da TAR aos mais diversos objetos de estudo.

Dentre os vários fenômenos sociais que passam a ser analisados pela ANT, tem-se o turismo (Beard, Scarles \& Tribe, 2016; Duim, Ren \& Jóhannesson, 2017). A TAR contribui para as pesquisas sobre turismo por conceder aos objetos papel central e também por destacar a composição dos híbridos, sendo válida como uma maneira de entender o processo de formação/organização de locais turísticos (Franklin, 2007). De forma geral, a ANT contribui para a compreensão das complexidades do turismo (Beard, Scarles \& Tribe, 2016).

Atualmente, tem-se enfatizado a necessidade da realização de estudos que permitam observar o turismo a partir de suas complexidades, essa é buscada pela adoção de abordagens diferenciadas do mainstream, sendo a abordagem convencional associada ao positivismo (Ren, Pritchard \& Morgan, 2010). Esse panorama mostra-se especialmente alarmante nas pesquisas brasileiras, em que as principais escolas de pensamento turístico imitam "a tradição positivista da epistemologia analítica e o funcionalismo alienante" (Panosso Netto \& Nechar, 2014, p. 137), promovendo análises que apresentam uma visão restrita do turismo (Panosso Netto \& Nechar, 2014; Panosso Netto, Noguero \& Jãger, 2011). Diante desse cenário, torna-se fundamental propor outras abordagens de análise para o turismo. Esse é o objetivo da presente pesquisa: apresentar a TAR como 'nova' abordagem ao estudo do turismo.

Apesar de aproximações entre turismo e ANT constituírem uma iniciativa antiga, remontando ao início dos anos 2000 (Duim, Ren \& Jóhannesson, 2017), no Brasil essa abordagem ainda é pouco utilizada e conhecida, constituindo assim um campo que 'merece' ser mais estudado (Duarte \& Teles, 2017) e discutido. Dessa forma, visando despertar o interesse de pesquisadores brasileiros sobre a TAR, o presente artigo mostra os principais fundamentos da teoria e suas críticas, seguido pela apresentação de uma breve análise bibliométrica sobre artigos ANT publicados em periódicos nacionais e internacionais de turismo, objetivando mostrar quais temáticas são mais discutidas e suas respectivas distribuições, por autores e instituições, destacando os periódicos mais relevantes para quem deseja iniciar os estudos sobre o tema. Por fim, enfatiza-se de que forma os temas são estudados nos periódicos.

\section{FUNDAMENTAÇÃO TEÓRICA}

A TAR trata dos vínculos e das relações que são estabelecidos entre os elementos que compõem um fenômeno. Mas não segundo a visão de vínculos sociais da sociologia 
tradicional de Durkheim, na qual se parte de uma análise macro (a sociedade) para explicar o micro (indivíduo), tendo que considerar aspectos contextuais para explicar os fenômenos sociais (Latour, 2012). Nesta se considera principalmente o elemento humano, negando que os objetos tenham importância. Em outras ocasiões, posiciona-se em diferentes planos analíticos pessoas e materiais. Para a TAR esse é um dos principais problemas da sociologia tradicional.

A TAR considera os vínculos que são formados entre pessoas, materiais, textos e todos os outros elementos que se encontram envolvidos, mesmo que de forma provisória, na composição de um fenômeno (Latour, 1994, 2012), sem colocá-los em diferentes classificações analíticas. Esse fundamento da ANT é criticado, tendo em vista que propõe o mesmo poder de ação a objetos e seres humanos, desconsiderando que a ação dos objetos é resultado da ação humana (Miller, 2005). E além do mais, acaba por atribuir aspectos exclusivamente humanos, a exemplo de identidade e relações, a objetos (Elder-Vass, 2008).

No entanto, Latour $(2012,2015)$ observa que não é possível outorgar a um indivíduo de forma isolada a origem da ação, o que seria por exemplo de um turista 'contemporâneo' sem seu smartphone, internet, redes sociais, aplicativos, meios de transporte e tantos outros fatores que, em parte, ajudam o turista a ser o que ele é. Dessa maneira, agir posiciona o indivíduo num imbróglio em que não é possível saber quem executou a ação e nem se quer identificar sua origem, assim se fala de ação a distância (Latour, 2015). Por isso, a TAR acredita que o actante e seus aspectos, como identidade, não existem fora de sua rede de relações.

Outra crítica se refere a questões de ordem ética, se seria correto atribuir o mesmo status a humanos e não humanos (Collins \& Yearley, 1992). No entanto, Law (2007) explica que essa igualdade se dá mais em termos analíticos do que ontológicos e que atualmente torna-se difícil ter uma definição segura do que é humano e não humano. A linha que separa as pessoas dos objetos está constantemente sujeita a negociações e mudanças (Law, 2007), tamanha é a dificuldade em classificar algo, que se opta por considerá-lo simplesmente como híbrido.

A partir da junção que é estabelecida entre esses híbridos em prol de um 'objetivo' comum, tem-se a composição da associação ou rede provisória. Portanto, a rede pode ser vislumbrada como tudo aquilo que é formado pelas associações de actantes (Latour, 2012; Mol, 2010), mas essa não é estabelecida materialmente, servindo apenas para ilustrar as relações estabelecidas. Ingold (2008), por outro lado, explica que a noção de rede apresentada nos estudos TAR passa a ideia de materialidade, pois é por meio da rede que os actantes fazem com que as coisas aconteçam. Assim, sugere que a expressão 'rede' seja substituída por malha, algo que vai aos poucos sendo tecida à medida que os actantes se movem. Além disso, entende que a sociedade não é uma composição de actantes conforme a ANT observa, mas um emaranhado complexo de fios e caminhos (Ingold, 2008).

Law (2007) reitera que as redes não são materiais, sendo formadas pelas relações heterogêneas que produzem e mesclam todo tipo de actante. Essas redes mostram-se como temporárias, isso porque dependem de negociações que são estabelecidas entre os actantes heterogêneos (Law, 2003; Mol, 2010). A qualquer momento um actante pode se desassociar, ou mesmo um novo elemento se associar à rede, o que torna o processo instável e indefinido. No entanto, são vividos momentos de estabilidade temporários (Law, 1992) e é justamente durante esses que o pesquisador consegue contar a história do fenômeno estudado. 
Ao debruçar-se sobre o estudo de um fenômeno, o objetivo da TAR é contar sua história de persistência (Latour, 2013). De acordo com a ANT, quanto maior for a força das associações, mais elevado é sua persistência, isso porque a força é medida pelo número de alianças que existem na rede e aquela rede que possui mais associados torna-se mais difícil de ser desfeita e persiste, e apenas o que resiste e permanece temporariamente estável tornase rastreável. E a TAR volta-se para contar a história daquilo que é rastreável.

Em parte, essa busca por contar a história da persistência dos fenômenos se deve à influência que a etnometodologia teve na construção dos pressupostos da ANT. Sendo assim, o resultado de uma pesquisa TAR é sempre a descrição densa, o que Latour (2012) denomina de relato, e em sua visão o bom relato é "uma descrição ou uma proposição na qual todos os atores fazem alguma coisa e não ficam apenas observando" (Latour, 2012, p. 189).

Para White e Spice (2008), a ANT mostra-se como uma abordagem pouco crítica, à medida que fica restrita exclusivamente às descrições dos fenômenos. No entanto, Latour (2012) enfatiza que uma boa descrição apresenta naturalmente em seu escopo explicações sobre os fenômenos. Essa afirmação é corroborada por Duim, Ren e Jóhannesson (2017) ao destacar a importância da teoria como um instrumento que gera descrições profundas das práticas turísticas que permitem perceber melhor como o turismo de fato acontece.

Ao promover o que White e Spice (2008) observam como descrições, a TAR não deveria ser vista como uma teoria, ao menos não em termos 'científicos'. A classificação da ANT como teoria é criticada até mesmo por seus fundadores (Callon, 1999; Latour, 1999; Law, 1992, 2007), que na falta de um termo melhor para nomeá-la mantém sua designação (Latour, 2012). Assim, Mol (2010) propõe observar a TAR a partir de uma nova visão de teoria.

[...] A força da ANT não está na sua coerência e previsibilidade, mas no que à primeira vista, ou aos olhos dos que gostam de suas teorias firmes, pode parecer ser a sua fraqueza: a sua adaptabilidade e sensibilidade. Se a ANT é uma teoria, então uma teoria ajuda a contar casos, desenhar contrastes, articular camadas silenciosas, deixar as perguntas de cabeça para baixo, concentrar-se no inesperado, adicionar à sua sensibilidade, propor novos termos e mudar histórias de um contexto para outro. (Mol, 2010, p. 262, tradução nossa).

Independente das críticas feitas à TAR, o fato é que suas ideias já serviram e ainda servem como base para a elaboração de diversas pesquisas, e isso se deve, especialmente, aos seus princípios. Dessa forma, nas subseções seguintes são apresentados e discutidos três de seus principais conceitos-chave ou princípios, assim como os estudos que embasaram sua construção.

\section{SIMETRIA GENERALIZADA E A INFLUÊNCIA DO PROGRAMA FORTE DE DAVID BLOOR}

O princípio da simetria generalizada teve como fundamento as ideias desenvolvidas por David Bloor em seu programa forte. Ao indagar as normatizações impostas no processo de formação do conhecimento científico, Bloor (2009) entende que elementos 'sociais', como cultura, sociedade, relações de poder, etc., encontram-se entrelaçados com conteúdo científico, sendo necessário analisá-los da mesma forma e conjuntamente. 
Assim, para Bloor (2009), deve-se utilizar os mesmos termos explicativos/métodos para estudar aquilo que é racional e irracional, verdadeiro e falso, sucesso e fracasso, etc.; não cabendo, portanto, nenhum tipo de rotulação, tudo é visto como uma composição. É a partir da abordagem simétrica desenvolvida por Bloor (2009) que o princípio da simetria generalizada é formado pelos idealizadores da TAR, guardando suas devidas diferenças.

Enquanto para Bloor (2009) as explicações sobre elementos como natureza e sociedade são feitas pelos seres humanos (sociedade), para a ANT as explicações partem de entes compostos por humanos e não humanos (quase-sujeitos e quase-objetos) (Latour, 1994). Esses podem ser conceituados como junções entre pessoas e objetos e ao se aproximar mais de um polo, por exemplo, das pessoas, tornam-se quase-sujeitos e vice-versa.

A TAR questiona a noção de pureza tão perseguida pela ciência, isso não significa que os estudiosos da ANT acreditem na inexistência de algo puro ou verdadeiro, mas que essa torna-se inacessível. Assim, partir dos quase-objetos e quase-sujeitos significa que, em vez de utilizar aspectos da natureza ou da sociedade como argumentos explicativos, entende que o conhecimento é formado no ponto médio por meio dos híbridos entre natureza e sociedade. O conhecimento não se dá, simplesmente, por meio de um sujeito cognoscente de um lado e um objeto inanimado a ser desvendado do outro. O que ocorre são cadeias de referências que constroem o conhecimento por meio dos híbridos (Latour, 1994, 2013).

Assim, por meio do princípio da simetria generalizada, não é possível afirmar a priori quais actantes são mais importantes para o estudo de um fenômeno, por isso o pesquisador deve estar aberto a observar empiricamente todos os aspectos relativos à formação da rede que dá origem ao fenômeno estudado. Isso pode ser percebido na seguinte afirmação:

Essa visão sublinha que não podemos decidir de antemão quais dos atores nas redes de turismo tem maior importância. [...] Não podemos saber se os turistas são mais importantes na formação do lugar turístico do que as empresas e a comunidade local ou que papel as atrações naturais desempenham nas redes particulares até rastrearmos as práticas e as relações nas quais o turismo emerge. Em vez de começar com o efeito de rede e explicar a partir daí, a ANT propõe descrever a rede (Jóhannesson, 2005, p. 139, tradução nossa).

Há estudiosos que vislumbram essa indefinição, qualquer elemento a qualquer momento pode se tornar um actante, como uma falha da TAR, isso significa que a teoria se mostra instável e pouco firme. E ainda há críticas afirmando que o princípio da simetria generalizada faz com que se ignore a alteridade, o que pode trazer consequências desastrosas para a elaboração de estudos críticos (Lee \& Brown, 1994). Mas Law (2007) explica que os humanos e não humanos não são a mesma coisa, e sim precisam ser analisados da mesma forma, pois têm a mesma importância em termos de agenciamentos (realização da ação). Isso faz com que a alteridade entre os actantes seja respeita e não ignorada.

\section{A TRANSLAÇÃO E OS ESTUDOS DE TEMPO DE MICHEL SERRES}

O conceito de translação é tão relevante para a TAR que, por vezes, utiliza-se a denominação 'sociologia da translação' como sinônimo de ANT. Além disso, frequentemente, utilizam-se os momentos de translação como método de pesquisa. 
O princípio da translação tem origem nos estudos sobre tempo de Serres (1996). De acordo com sua visão, o tempo não se dá linearmente, mas ao contrário, ocorre de forma caótica, fluindo de maneira complexa e inesperada. Os acontecimentos históricos são multitemporais, pois no passado, presente e futuro coexistem simultaneamente.

[Pense num carro] de um modelo recente: constitui um agregado heterogêneo de soluções científicas e técnicas de épocas diferentes; podemos datá-la peça por peça: este órgão foi inventado no começo do século, aquele há 10 anos e o ciclo de Carnot tem quase 200 anos. Sem contar que a roda remonta ao neolítico. O conjunto não é contemporâneo a não ser pela sua montagem, desenho, carroçaria, por vezes pela pretensão da publicidade (Serres, 1996, p. 64). [...] Toda a gente se espanta de os nazistas, depois de 1935, se entregarem aos comportamentos mais arcaicos, no país mais avançado do mundo, nas ciências e na cultura. Ora fazemos, sem cessar, ao mesmo tempo gestos arcaicos, modernos e futuristas (Serres, 1996, p. 86).

Assim, ao entender os acontecimentos históricos como uma composição que mistura elementos heterogêneos de passado, presente e futuro, ao mesmo tempo, Serres acaba por desenvolver seu conceito de translação, sendo esse entendido como o processo de formar conexões ou estabelecer aproximações, no sentido que representa a ação que faz com que a associação seja formada. Mas esse não consiste num processo que é necessariamente fácil, pois os actantes podem possuir interesses diversos, nesses casos como é feita a translação?

Callon (1986) explica esse processo por meio de quatro diferentes momentos. No primeiro tem-se a problematização, a qual estabelece as bases para fazer com que um actante (ou grupo) se torne indispensável. Nesse momento tem-se a estabilização do actante como ponto de passagem obrigatória (PPO), ou seja, um actante que leva outros a confluir suas demandas num único ponto para que todos possam alcançar seus objetivos. Apenas a partir dessas definições em comum é que o processo de translação pode continuar (Callon, 1986).

No momento seguinte (interessamento), são tomadas ações para que uma entidade atraia a maior quantidade possível de actantes, tornando a associação mais forte. Assim, as identidades do grupo são consolidadas ou (re)definidas, buscando ao máximo interromper possíveis disputas, para que seja construído um sistema de alianças. No terceiro momento (inscrição) são definidos papéis e estratégias que devem ser seguidos por todos para estabelecer unidade, instituindo-se um porta-voz. As regras são apresentadas aos atores, e caso essas sejam aceitas por todos, consolida-se uma aliança entre os actantes (Callon, 1986).

No último momento (mobilização), há a composição de todos os aliados para reafirmar a representatividade do porta-voz. Caso haja alguma contestação, tem-se a dissidência, se não houver, o coletivo é temporariamente mantido. Depois da mobilização há movimentos de contestações, dissidências e chegada de novos actantes. Essa dinâmica leva Latour (2012) a afirmar que não há grupos prontos, mas apenas processos de formação de grupos.

Apesar da importância da translação para TAR e de seus momentos servirem como arcabouço metodológico em pesquisas (Walsham, 1997), esse conceito é visto por alguns como determinístico e mecanicista. Isso porque a descrição dos momentos de translação mostra uma abordagem prescritiva, ao propor regras para que translação ocorra e tem-se, assim, a imposição da forma como os actantes se associam (Alcadipani \& Tureta, 2009). 
A translação implica a produção de novas relações, encontros e negociações, o que significa que ocorrem modificações na composição da rede, sendo assim, a translação é vista como traição (Law, 2007), no sentido de que não leva a manutenção do status inicial. Assim, associou-se a translação à desordem e à precariedade, já que basta um dos movimentos de translação falhar para que todo o processo de produção daquela realidade falhe.

Dessa maneira, nos recentes estudos de Latour (2013) e Law (2007), em vez de analisar como os objetos se estabilizam por meio da translação, observa-se como são produzidas as redes de realidade; e, para entender essa produção, lança-se mão da performatividade.

\section{O MOVIMENTO PÓS-ANT E A NOÇÃO DE PERFORMATIVIDADE}

Ao observar as críticas realizadas à TAR, especialmente no que se refere à ideia da translação, são propostas algumas 'torções na teoria' (Camillis \& Antonello, 2016), as quais recebem o nome de pós-ANT (Callon, 1999; Latour, 1999), e uma dessas torções refere-se à ascensão da performatividade como novo aporte de estudo da TAR.

A origem dos termos performativity, performances e performative nos estudos ANT tem sua origem relacionada às ideias de Mol (2002) e Law e Mol (1995). Nessas, apresenta-se a performatividade (Law \& Mol, 1995) ou a enactament (Mol, 2002) como sendo uma forma de produção das redes de realidade por meio das práticas. O enactment propõe a formação de realidades múltiplas, isso porque, para Mol (2002), as realidades são formadas pelas práticas, logo, tendo em vista que existem práticas variadas, também há diversas realidades sendo enactadas. Isso implica uma proposição diferenciada da translação, a qual observa a composição de uma rede de realidade e não de muitas.

As realidades adquirem caráter múltiplo não porque são interpretadas de várias formas (perspectivismo), mas em decorrência das muitas práticas que ajudam a formar. Não é que as práticas expliquem as realidades, as práticas compõem as redes de realidades.

No entanto, o enactar não deve ser confundido com a construção, como se as realidades fossem fabricadas como objetos, isso porque não adquire uma identidade fixa ou determinada que não é possível ser alterada, ao menos que seja destruída e refeita. $\mathrm{O}$ enactar consiste num 'artesanar' constante, ao qual as práticas nunca param. Além do mais, não é um simples o processo a se fazer, pois, ao performar uma realidade, também se é impactado por ela. Na medida em que o actante passa a se relacionar com outros elementos para compor uma rede heterogênea, tanto influencia outros actantes como é influenciado por eles, por isso Law (2004) enfatiza a reciprocidade do enactar/performar.

\section{METODOLOGIA}

O termo bibliometrics (bibliometria) aparece pela primeira vez em Pritchard (1969). Ele é explicado como sendo a aplicação de métodos matemáticos e estatísticos em livros e outras comunicações escritas, com o objetivo de estudar de forma quantitativa todo o processo de escrita de uma determinada área de conhecimento.

A bibliometria é entendida como um instrumento que visa acompanhar o desenvolvimento de um ou vários campos de conhecimentos, pois se acredita que, por meio 
das produções científicas, é possível perceber as evoluções nas áreas de conhecimento. Por vezes, os estudos bibliométricos buscam rastrear referências citadas, autorias, publicações ou palavras, mas eles não precisam se restringir à mera contagem, pode-se analisar as conexões existentes entre os temas que são rastreados, ou mesmo entre autores e instituições, o que fornece algumas indicações sobre a evolução dos estudos de um campo (Porter, 2007).

\section{SELEÇÃO DA AMOSTRA DA PESQUISA}

A seleção dos periódicos nacionais de turismo para compor o escopo dessa pesquisa foi feita a partir do portal de periódicos da Comissão de Aperfeiçoamento de Pessoal do Nível Superior (CAPES), enquanto que os internacionais por meio da Scopus (Elsevier). A razão para a escolha dessas bases de dados se deve, principalmente, ao critério relevância. No caso do portal da CAPES, há vários estudos bibliométricos que utilizam o referido portal para levantar a produção científica brasileira de determinada área de conhecimento (Emerich, 2017; Machado \& Macêdo, 2016), situando-o como a base de dados 'oficial' dos estudantes de pós-graduação do país. A escolha pela Scopus deu-se por se tratar de uma das três principais bases de dados internacionais (Jacson, 2005) e devido aos critérios de busca mais intuitivos que possui, onde se torna possível delimitar de forma fácil as subáreas a serem analisadas.

Dessa forma, dentro da base de dados Scopus, fizeram-se buscas no critério fonte, em que se selecionou a subárea 'turismo, lazer e gestão da hospitalidade'. A partir dela, chegouse a 97 periódicos. Optou-se por reduzir a amostra, para realizar análises mais profundas dos artigos, assim se utilizou como critério o CiteScore ${ }^{1}$ da Scopus, aqueles periódicos com índice igual ou superior a 2 foram considerados, resultando em 23 periódicos internacionais.

Com relação aos nacionais, em decorrência da pouca quantidade de periódicos classificados na CAPES na área turismo², recorreu-se à busca por meio do título, assim, primeiramente delimitou-se como critério "Classificações de periódicos quadriênio 20132016", depois se colocou como área de avaliação "administração pública e de empresas, ciências contábeis e turismo" e, por fim, no campo título, foram inseridas as expressões 'turismo', 'lazer' e 'hospitalidade', uma por vez. A escolha por essas palavras se deve a uma tentativa de aproximação com os critérios utilizados nas buscas feitas na Scopus. Essa seleção retornou em 33 periódicos, dentre esses se observaram apenas aqueles nacionais com estrato igual ou superior a B3, resultando num total de 13 títulos.

Os periódicos nacionais e internacionais selecionados são listados no Quadro 1.

\begin{tabular}{|l|l|l|l|}
\hline PERIÓDICOS INTERNACIONAIS & $1^{*}$ & PERIÓDICOS NACIONAIS & $2^{* *}$ \\
\hline Annals of Tourism Research & 3.68 & Anais Brasileiros de Estudos Turísticos (ABET) & B3 \\
\hline Applied Geography & 3.75 & Caderno Virtual de Turismo (CVT) & B1 \\
\hline Cities & 3.61 & Revista Acadêmica Observatório de Inovação do Turismo & B2 \\
\hline Cornell Hospitality Quarterly & 2.15 & Revista Brasileira de Ecoturismo & B3 \\
\hline Current Issues in Tourism & 2.85 & Revista Brasileira de Pesquisa em Turismo & A2 \\
\hline European Sport Management & 2.25 & Revista de Economia, Adm. e Turismo & B3 \\
\hline
\end{tabular}

1 Calculado com base no total de citações acumuladas nos últimos três anos (2015, 2016 e 2017).

2 Ao buscar no portal de periódicos da CAPES pela área de conhecimento 'Ciências Sociais Aplicadas' e subárea 'Turismo', tem-se como retorno 74 periódicos, sendo apenas 6 nacionais, a saber: Caderno Virtual de Turismo, Cadernos Gestão Social, Revista de Gestão do UNILASALLE, Diálogo com a Economia Criativa, Revista Turismo em Análise, Turismo e Sociedade. O que se notou é que a maioria dos periódicos de turismo nacionais se encontram classificados como multidisciplinares, e estão em outras áreas de conhecimento ou sequer constam classificados dentro de uma área específica de conhecimento. 


\begin{tabular}{|c|c|c|c|}
\hline $\begin{array}{l}\text { International Journal of } \\
\text { Contemporary Hospitality } \\
\text { Management }\end{array}$ & 3.59 & Revista de Turismo Contemporâneo & B3 \\
\hline $\begin{array}{l}\text { International Journal of Hospitality } \\
\text { Management }\end{array}$ & 4.1 & Revista Eletrônica de Administração e Turismo (ReAT) & B3 \\
\hline $\begin{array}{l}\text { International Journal of Tourism } \\
\text { Research }\end{array}$ & 2.77 & Revista de Hospitalidade & B3 \\
\hline $\begin{array}{l}\text { Journal of Hospitality and Tourism } \\
\text { Management }\end{array}$ & 2.18 & Revista Iberoamericana de Turismo & B3 \\
\hline $\begin{array}{l}\text { Journal of Hospitality and Tourism } \\
\text { Research }\end{array}$ & 3.69 & Revista Turismo em Análise & B1 \\
\hline $\begin{array}{l}\text { Journal of Hospitality Marketing and } \\
\text { Management }\end{array}$ & 2.28 & Rosa dos Ventos (Turismo e Hospitalidade) & B2 \\
\hline $\begin{array}{l}\text { Journal of Hospitality, Leisure, Sport } \\
\text { and Tourism Education }\end{array}$ & 2.48 & Turismo: Visão e Ação & B1 \\
\hline Journal of Service Management & 4.08 & & \\
\hline Journal of Sustainable Tourism & 3.64 & PERÍODICOS INTERNACIONAIS & 23 \\
\hline $\begin{array}{l}\text { Journal of Travel and Tourism } \\
\text { Marketing }\end{array}$ & 2.08 & PERIÓDICOS NACIONAIS & 13 \\
\hline Journal of Travel Research & 4.92 & TOTAL GERAL: & 36 \\
\hline Leisure Studies & 2.41 & & \\
\hline $\begin{array}{l}\text { Research in Transportation Business } \\
\text { and Management }\end{array}$ & 2.4 & \multirow{5}{*}{$\begin{array}{l}* 1 \text { - CiteScore da Scopus } \\
* * 2 \text { - Estrato Qualis da CAPES }\end{array}$} & \\
\hline Sport Management Review & 3.28 & & \\
\hline Tourism Geographies & 2.41 & & \\
\hline Tourism Management & 6.9 & & \\
\hline Tourism Management Perspectives & 2.55 & & \\
\hline
\end{tabular}

Após selecionar os periódicos, realizaram-se buscas por termos, em que, além de teoria ator-rede (actor-network theory/teoria del actor-red), também se buscaram pelas palavras translação (translation/ translación), performatividade (performatividad, performance, performative e performativity) e simetria generalizada (simetría generalizada/ generalized symmetry).

No caso dos periódicos internacionais, a busca pelos termos foi feita na Scopus, em que se selecionaram artigos como tipo de documento. No critério periodicidade foram escolhidos 'todos os anos' até 2017 e a busca foi feita a partir dos títulos de artigos, resumos e palavras-chave. Assim, após selecionar esses critérios, bastou inserir o título dos periódicos um por vez.

Por outro lado, nos periódicos nacionais, tornou-se necessário entrar no site de cada um deles para realizar as buscas. No site dos periódicos brasileiros, foram utilizados os mesmos critérios definidos para a busca dos periódicos internacionais (termos, tipo de documento, periodicidade e locais de busca no artigo - título de artigo, resumo e palavraschave), inclusive a pesquisa foi feita usando os termos em inglês e espanhol, tendo em vista a presença de artigos em outras línguas em periódicos de turismo brasileiros. 


\section{ANÁLISE DOS DADOS}

A princípio foi necessário realizar um tratamento nos dados, isso porque, ao observar os artigos que possuem os termos buscados, notou-se que, em alguns casos, aparecem com outro sentido. Por exemplo, na maioria dos artigos do periódico Applied Geography a expressão translation aparece no sentido de tradução, como uma nota nos resumos, afirmando que os artigos foram traduzidos para o inglês. Em outros periódicos, como Tourism Management, Leisure Study, Observatório de Inovação do Turismo, Revista de Hospitalidade, e Turismo em Análise, a mesma expressão se encontra associada à Teoria da Tradução.

E com relação aos termos voltados à performatividade, em vários periódicos nacionais e internacionais aparecem associados ao desempenho econômico. Dessa maneira, quando os conceitos-chave da TAR são apresentados com outro sentido, além daqueles discutidos nas subseções anteriores, os artigos não foram considerados, o que demandou uma análise prévia dos dados para entender se esses devem ou não compor a amostra da pesquisa.

Houve casos em que diferentes termos apareceriam num mesmo artigo, por exemplo, teoria ator-rede e performatividade, nessas situações o artigo era duplamente enquadrado, uma vez como sendo um artigo que trata da TAR e outra associando-o à performatividade. No entanto, ao fazer a contagem total geral essa dupla incidência, era descartada, sendo contado apenas uma vez cada artigo. Isso aconteceu em vários periódicos, como a Annals of Tourism Research, ABET, Current Issues in Tourism e Tourism Management.

Após a definição da amostra, tendo em vista a realização de uma bibliometria, foram feitas análises de estatística descritiva para ilustrar a quantidade de produção de pesquisas e suas respectivas distribuições. Depois da análise estatística básica, foi feito um agrupamento temático das principais formas em que a TAR e seus conceitos-chave são estudados.

\section{APRESENTAÇÃO DOS RESULTADOS DA PESQUISA}

Nessa seção são apresentados, de forma breve, os resultados referentes, primeiramente, às estatísticas descritivas sobre os artigos analisados e, posteriormente, às temáticas mais trabalhadas/discutidas pelos artigos analisados.

\section{ESTUDO BIBLIOMÉTRICO EM PERIÓDICOS NACIONAIS E INTERNACIONAIS}

O único periódico nacional que retornou resultados para os termos pesquisados com o sentido apresentado nessa pesquisa foi o ABET, com a presença de 4 artigos, sendo que todos eles estão relacionados aos termos teoria ator-rede (em espanhol, teoria del actor red) e um deles, além da ANT, faz uma discussão sobre performatividade. No entanto, com relação aos periódicos internacionais, o panorama é bastante diferenciado, e nesses foram encontradas 53 ocorrências. Dessa forma, ao total, foram encontrados 57 artigos que tratam de temas relacionados à TAR. Na Figura 1, pode-se visualizar a produção de pesquisas em turismo sobre TAR e seus conceitos afins (translação e performatividade) distribuídos por ano. 


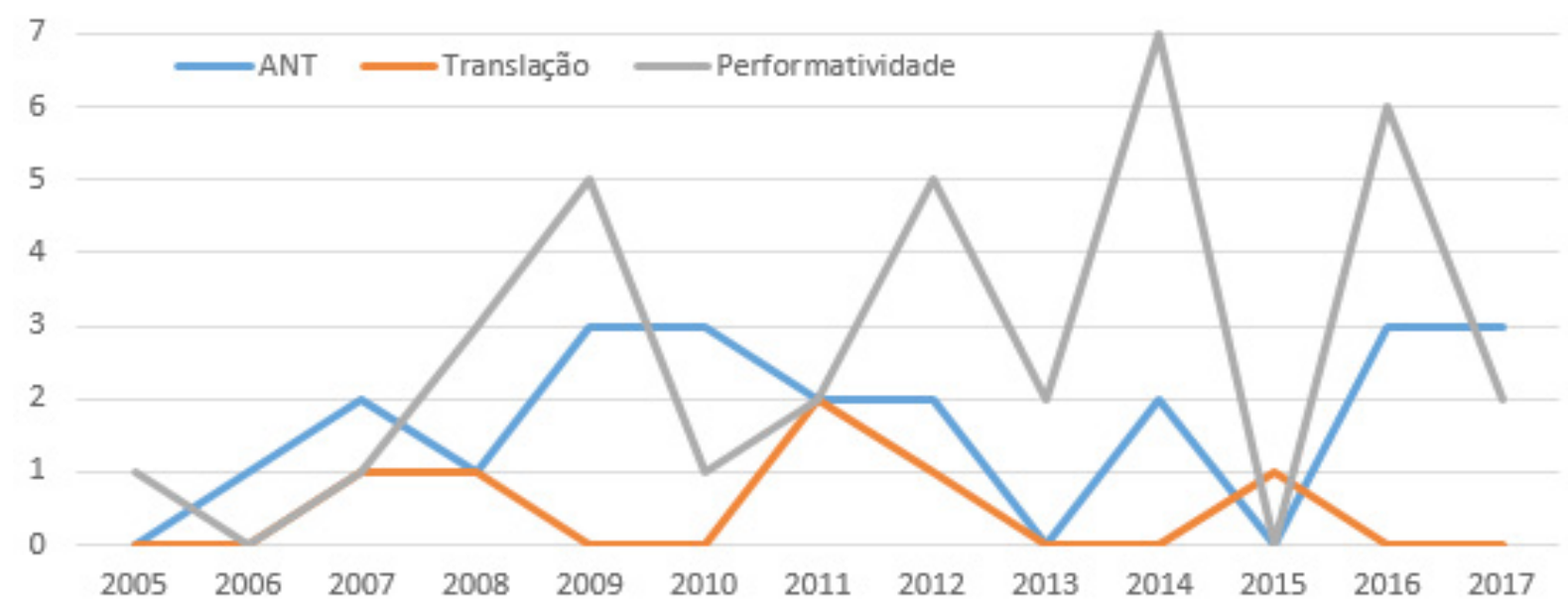

Figura 1. Distribuição da Produção sobre TAR e afins em periódicos nacionais e internacionais Fonte: Dados da Pesquisa (2018).

O que primeiro fato que chama atenção na Figura 1 é a inexistência do termo simetria generalizada. Ele não foi encontrado no título, no resumo ou nas palavras-chave de nenhum dos artigos analisados. Por outro lado, ao fazer uma leitura dos artigos, notou-se que no corpo do texto a ideia de simetria entre humanos e não humanos está presente, mas não aparece como a temática principal das pesquisas. Outro fato claramente percebido é a pouca produção de artigos enfatizando a translação/momentos de translação, que é considerado por Walsham (1997) como um dos principais 'métodos' utilizados nas pesquisas TAR.

A partir da Figura 1, não se nota uma clara tendência de evolução dos temas, o que se percebe é que a temática performatividade apresenta resultados mais expressivos, o que pode reafirmar a posição de Harwood e El-Manstrly (2012) acerca de uma virada para a performatividade nas pesquisas sobre turismo no mundo.

Com relação à autoria, quem mostrou uma maior quantidade de publicações foi René van der Duim, com 6 artigos; seguido por Carina Ren e Samuel Gaitán, com 3 produções cada. Ainda aparecem Scott Cohen, Erik Cohen, John Tribe, Mordue, Melanie Watt e Peter Lugosi, com 2 artigos cada; os demais autores aparecem uma vez em cada publicação, o que pode indicar uma distribuição de autoria nas pesquisas TAR. No entanto, essa distribuição não acontece com os artigos publicados pela ABET, em que três dos quatro são de autoria de Gaitán.

Notou-se também uma grande concentração de pesquisadores associados a instituições internacionais europeias, com maior destaque para o Reino Unido (com 20 publicações). Poucas produções têm origem em instituições da América Latina, dos mais de cinquenta artigos pesquisados, há somente três autores de instituições latinas, sendo apenas um deles de instituição brasileira (Marcelo Bispo) da Universidade Federal da Paraíba (UFPB).

A seguir, na Figura 2, encontra-se a distribuição de artigos por periódico, a partir desse é possível perceber uma grande concentração de publicações na revista Annals of Tourism Research, que apresenta quase metade de todas as publicações sobre a temática pesquisada. 


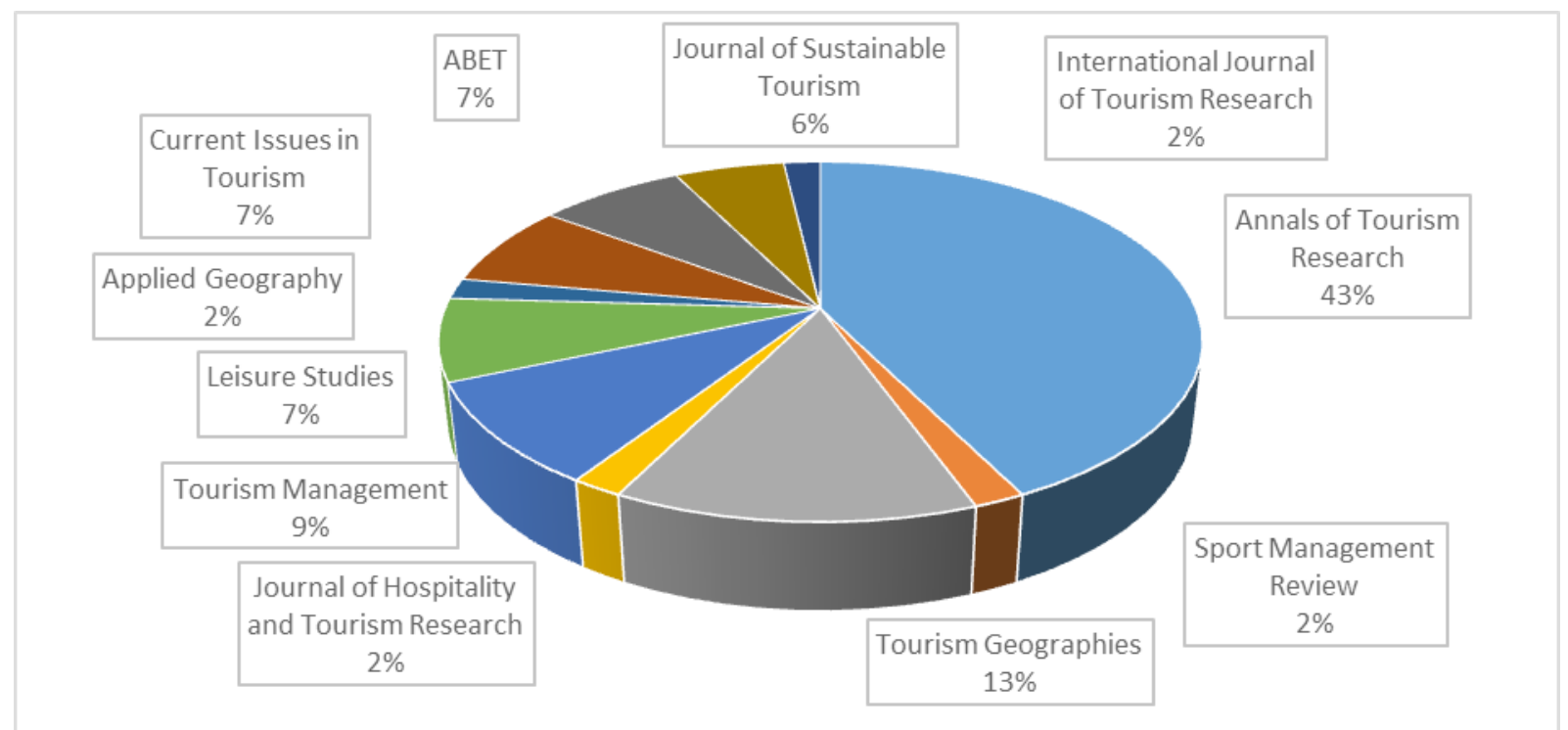

Figura 2: Quantidade de artigos publicados por periódicos Fonte: Dados da Pesquisa (2018).

Apesar do periódico Tourism Management de forma geral possuir maior CiteScore e mais artigos do que a Annals of Tourism Research, com relação à temática estudada, a produção da Annals of Tourism Research mostrou-se bem superior, tanto em termos de quantidade de artigos como em citações. Os dois artigos mais citados da Annals of Tourism Research de forma isolada, Duim (2007) e Cohen e Cohen (2012), possuem mais citações do que a soma de todos os artigos sobre o tema publicados pela Tourism Management.

\section{DISCUSSÕES TEMÁTICAS SOBRE TAR NOS PERIÓDICOS NACIONAIS E INTERNACIONAIS}

As discussões temáticas que são apresentadas nos artigos dos periódicos nacionais e internacionais são divididas em subgrupos, com o intuito de melhor descrevê-las. Assim, o primeiro grupo diz respeito aos artigos nos quais foram encontrados termos associados à ideia da teoria ator-rede, no segundo aqueles relacionados à translação e, por fim, performatividade.

\section{PESQUISAS EM TURISMO ACERCA DA TEORIA ATOR-REDE}

Notaram-se predominantemente dois temas principais relacionados aos artigos sobre TAR e turismo. Em um dos grupos, tem-se uma clara preocupação em discutir a composição da rede/malha do turismo, e em algumas dessas pesquisas essa discussão ocorre de forma mais conceitual, explicando os constantes processos de organização dos actantes que resultam na formação do turismo. Em outras pesquisas, faz-se uma discussão similar, no entanto, situando-as empiricamente, apresentando sempre locais onde se realiza uma análise da forma como o turismo se formou por meio da composição de seus actantes.

O artigo de Duim (2007), por exemplo, é um dos primeiros a fazer uma discussão conceitual sobre os elementos que compõem a associação do turismo, ao qual Duim (2007) 
denomina tourismscape. Para o autor, tem-se pelo menos três elementos que compõem o tourismscape. São eles: os corpos, objetos/espaços e informações/mídia. No entanto, os elementos citados por Duim (2007) não devem ser vistos de forma reducionista, quando se fala em corpos, envolve aquilo que se pode realizar com os mesmos, a exemplo do olhar (Larsen \& Urry, 2011), das conexões mentais, dos exercícios físicos, do paladar, do cheiro, etc., e o mesmo pode ser dito com relação aos outros elementos (objetos, espaços, informações e mídia).

Gaitán $(2012$, 2014) faz uma análise parecida à feita por Duim (2007), porém volta seu estudo para a formação do espaço como produto turístico, observando como a composição acontece de forma múltipla e fluida em Tafi del Valle (Argentina). Esse processo, que Duim (2007) entende como tourismscape, para Gaitán (2014), é um entramado turístico, composto também por múltiplos elementos que compõem o produto turístico.

Ilustrando a ideia da complexidade do entramado turístico (Gaitán, 2012, 2014) e do tourismscape (Duim, 2007), Hummels e Duim (2016) trazem, como exemplo, a influência que os organismos internacionais têm de modificar os projetos de desenvolvimento de alguns países, representando um exemplo claro de ação a distância (Latour, 2015).

Vários outros exemplos empíricos são apresentados, sempre enfatizando a composição múltipla do turismo. Mordue (2009), ao discorrer sobre a composição do turismo de pesca, faz uma 'viagem' por diferentes países, enfatizando a multiespacialidade e a multitemporalidade, que apresentam relação com o conceito de translação desenvolvido por Serres (1996). Além desses elementos, Mordue (2009) ainda enfatiza a presença de aspectos voltados à natureza para descrever como essa forma de lazer se organizou e acabou por ganhar destaque na Inglaterra. Mas não só formas de turismo relacionados à natureza são destacadas, há artigos que se voltam para discutir a organização de destinos culturais.

Arnaboldi e Spiller (2011) observam como stakeholders podem, por meio de conceitos criados pela TAR (mobilização de atores, translação e construção dos fatos), auxiliar na composição de um distrito cultural. Nessa análise, as indicações da TAR são desdobradas em 14 problemas que precisam ser sanados para que se possa compor o distrito cultural, e em cada item são feitas especificações de como os stakeholders devem atuar para compor um distrito cultural na região montanhosa de Valsassina no norte da Itália.

Além dos estudos voltados para a composição dos destinos ou dos tipos de turismo, também há artigos que procuram analisar as pesquisas em turismo nos últimos anos. Em Tribe (2010), utilizam-se conceitos TAR como simetria entre humanos e não humanos para compor o que o autor chama de diferentes territórios do saber turístico. Já em Cohen e Cohen (2012), novas abordagens, a exemplo da ANT e da performatividade, são apresentadas como instrumentos que contribuem para o estudo do turismo, tornando suas análises mais críticas. Indicação similar é feita por Ren, Pritichard e Morgan (2010), os quais destacam ainda o importante papel das narrativas no estudo do turismo, inclusive como uma forma de melhor seguir as práticas turísticas contemporâneas (Duim, Ren \& Jóhannesson, 2017).

\section{PESQUISAS EM TURISMO SOBRE TRANSLAÇÃO}

Os poucos artigos que mencionam a translação se encontram, na maioria das vezes, diretamente relacionados às pesquisas sobre TAR, o que significa que, diferente da 
performatividade, a translação não conseguiu evoluir para além da teoria ator-rede, sendo não só associada a ela, mas dependente dela. Além disso, a maior parte das publicações pesquisadas que apresentam ideias voltadas para a ANT são redigidas pelo mesmo autor, Duim e Marwijk (2006), Duim (2007), Duim e Caalders (2008).

Em Duim e Marwijk (2006), apresenta-se como o método Product en MilieuZorg (PMZ) é implementado em operadoras de turismo da Alemanha por meio da Associação Holandesa de Operadores de Turismo. Esse processo de implementação faz com que o PMZ passe por processos de translação. À medida que sua implementação envolve a presença de actantes diferentes, acabam por adaptar alguns de seus princípios à realidade dos operadores alemães. Análise similar é realizada em Duim e Caalders (2008), mas dessa vez voltando-se para a implantação de um projeto de turismo pro-poor na Costa Rica.

Apenas no periódico Applied Geography aparece referência à translação, sendo essa associada à ideia de mudança, sem mencionar a TAR. Em Salvati, Mavrakis, Serra e Carlucci (2015), a translação é apresentada por meio da Spatial Cycle Theory (SCT), que é estruturada em quatro fases (urbanização, suburbanização, contra urbanização e reurbanização). Elas mostram o processo de formação espacial de forma complexa, em que se destacam a dinâmica e a composição do local com a participação de pessoas e demais elementos. De certa forma, o processo se assemelha aos momentos de translação explicados por Callon (1986).

\section{PESQUISAS SOBRE TURISMO ACERCA DA PERFORMATIVIDADE}

A maior parte dos estudos levantados nessa pesquisa utilizam o arcabouço da performatividade como fundamento teórico-metodológico, vide Figura 1. Nesses estudos notam-se variadas discussões acerca da performatividade, há pesquisas sobre autenticidade, performatividade como a composição de diferentes realidades turísticas que existem por meio das práticas, enfatizando distintos processos de organização do turismo e artigos que procuram fazer uma revisão sistemática dos estudos sobre performativity.

Com relação às discussões sobre a autenticidade da performatividade, aparece de forma similar àquela trabalhada no estudo clássico de MacCannell (1973), todavia com a grande diferença de que a autenticidade não é encenada unicamente como um atrativo turístico, mas é de fato incorporada por aqueles que a performam. Essa ideia de uma incorporação da 'autenticidade' aparece na formação de Dogma e na cerimônia de casamento apresentada por Zhu (2012), na postura dos donos de restaurante de Victoria Falls, os quais incorporam a 'autenticidade africana' quando elaboram seus sites e comunicações (Mkono, 2013), nas experiências autênticas dos turistas ao realizar turismo esportivo nos Alpes franceses (Lamont, 2013), no estudo sobre redes sociais e tecnologias de comunicação que auxiliam a moldar aquilo que se acredita ser autêntico (Lugosi, 2016), ou mesmo em estudos acerca da percepção da performação da autenticidade por turistas que visitam destinos ecoculturais (Tiberghien, Bremner \& Milne, 2017).

A formação dessa autenticidade se dá por meio de uma série de elementos (humanos e não-humanos), não é apenas o turista ou o mercado que a formam, mas um conjunto frequentemente extenso de elementos. E a participação desses elementos, no processo de 
composição turística, por vezes, pode parecer pouco convencional. Esse é o caso do estudo de Ren (2011), no qual apresenta o ocypek - queijo tradicional polonês - como um dos muitos elementos que ajudam a compor Zakopane como um destino turístico; ou mesmo no estudo de Diekman e Hamnam (2012), que observam como os filmes auxiliam na formação do turismo e na própria performação do turista na Índia; análise similar é feita por Urry (1996), que observa como St. Tropez como destino turístico é co-performado por Brigitte Bardot.

Em outras abordagens voltadas à performação, o turismo mostra-se como um elemento co-performador de processos de exclusão e gentrificação (Mordue, 2005), ou até mesmo como um actante que se mostra resistente ao processo de globalização cultural e ao consumo da cultura como mero produto capitalista (Jamal \& Camargo, 2014).

É interessante notar como um mesmo fenômeno apresenta realidades tão diversas, e é explicado pelas ideias de enactar desenvolvidas por Mol (2002), mostrando que o turismo não apresenta uma essência própria, e que a atividade é composta a partir de suas práticas (Bispo, 2016; Mol, 2002). Dessa maneira, não faz sentido procurar estabelecer modelos fixos para estudá-lo, isso porque o panorama encontrado em uma rede de realidades pode não se repetir em outra, o que o pesquisador deve fazer é se comportar como uma 'formiga' (ant) buscando vestígios (Latour, 2012) para rastrear os fenômenos que estuda, e a partir da prática dos actantes ir aos poucos tecendo a rede/malha que forma o turismo.

\section{CONSIDERAÇÕES FINAIS}

A análise feita nesse artigo, ao trilhar os caminhos da produção em ANT relacionada ao turismo, mostra que conceitos bastante importantes dentro da Teoria Ator-Rede, como translação e simetria generalizada, acabam não sendo tão utilizados nos artigos pesquisados. Isso pode ocorrer, no caso da translação e de seus momentos, devido a uma restrição própria dessa forma de comunicação. Fazer uma narração de um processo de formação/organização do turismo requer uma descrição densa e extensa, o que demanda grande quantidade de laudas, logo essa forma de pesquisa torna-se mais adequada de ser realizada por uma dissertação ou tese, e não por um artigo científico, ao qual requer comunicação mais direta. Mas isso não significa que essas temáticas se encontram fora dos artigos pesquisados, pois em várias ocasiões suas ideias foram identificadas no corpo dos textos.

Além disso, esse resultado pode estar relacionado a alguma limitação da pesquisa, tendo em vista que a pesquisa possui limitações com relação ao escopo da pesquisa, ao restringir suas análises a periódicos com CiteScore igual ou superior a 2 e estrato Qualis no mínimo B3, acabando por excluir periódicos que possuem análises sobre o fenômeno estudado. Dessa maneira, notou-se que, fora desses critérios, enquadra-se a revista Turismo \& Sociedade, um periódico nacional que já apresenta artigo sobre a temática, e de forma similar se percebeu que a revista Tourist Studies também apresenta produções, algumas muito citadas.

Isso ficou claro não só ao ler o conteúdo dos artigos selecionados na amostra, mas também ao inseri-los no software CitNetExplorer e mapear suas redes de referências. Nessa análise, são citadas como referências bibliográficas mais utilizadas: Latour (2012 [2005]), Duim (2007), Edensor (2001) e Johánnesson (2005), respectivamente, e dessas, as duas últimas são publicações realizadas no periódico Tourist Studies. Também apareceram outras citações a artigos da Tourist Studies, a exemplo de Fullagar (2001) e Franklin (2004) e, assim, pode-se 
observar que o referido periódico em conjunto com a Annals of Tourism Research consistem em importantes fontes de pesquisa para aqueles que querem estudar o turismo e a TAR.

Desse modo, para os pesquisadores brasileiros dispostos a se aventurar pelos caminhos da TAR é possível observar como os estudos ANT e seus pressupostos voltam-se principalmente para descortinar o enactar da autenticidade, a composição complexa que é o fenômeno turístico e as múltiplas formas de organização do turismo. Nota-se, claramente, que essas duas últimas temáticas se encontram extremamente relacionadas, pois ao pensar no turismo como uma composição complexa, devido à quantidade de actantes que possui, acaba por desencadear na formação dos vários processos de organização ou realidades turísticas.

Isso implica a presença de uma grande quantidade de actantes, por vezes, inesperados, como botas de cowboy, queijo polonês, charutos cubanos, filmes e erupções vulcânicas (Picken, 2010). Esses elementos ilustram como de fato a agência dos destinos turísticos é extensa, corroborando o princípio de que a rede que compõe o turismo não consegue ser definida de antemão, e apenas a partir de observações em campo, seguindo os actantes, é possível começar a traçar a rede. E na 'prática' isso significa ir a campo sem ter ideia da extensão da rede (ou seja, da quantidade de actantes que deve seguir para entender o fenômeno estudado ou mesmo sem precisar por quais locais irá passar, pois conforme afirma Latour (2015), a ação é distribuída temporal, espacial e relacionalmente).

Apesar das indicações propostas parecerem simples, para os pesquisadores, acostumados com os preceitos positivistas e com suas teorias 'fortes' (Latour, 1994; Mol, 2010), ir a campo sem nenhuma definição, mantendo-se aberto a perceber a importância de qualquer elemento, inclusive daqueles anteriormente vistos como sem importância, considerando que a realidade estudada pode ser refeita, é uma atividade extremamente difícil, que demanda um esforço por parte do pesquisador para romper inclusive com suas práticas rotineiras de pesquisa, adotando uma postura totalmente nova ao ir a campo.

\section{REFERÊNCIAS}

Alcadipani, R.; Tureta, C. (2009) Teoria Ator-Rede e análise organizacional: contribuições e possibilidades de pesquisa no Brasil. Organização \& Sociedade, 16 (51), 647-664.

Arnaboldi, M. \& Spiller, N. (2011) Actor-network theory and stakeholder collaboration. Tourism Management, 32, $641-654$.

Beard, L., Scarles, C., \& Tribe, J. (2016) Mess and method: using ANT in tourism research. Annals of Tourism Research, 60, 97 - 110.

Bispo, M. de S. (2016) Tourism as practice. Annals of Tourism Research, 61, 170 - 179.

Bijker, W. E. (1986) Introduction. In Bijker, W. E., Hughes, T. P., \& Pinch, T. (Eds.). The social construction of technological systems (Chap. 1, pp. 9 - 16) Cambrigde: MIT Press.

Bloor, D. (2009) Conhecimento e imaginário social [2. Ed]. São Paulo: UNESP.

Callon, M. (1999) Actor-network theory: the market test. In Law, J. \& Hassard, J. Actor-Network theory and after. Oxford: Blackwell Publishers. 
Callon, M. (1998) The embeddedness of economic markets in economics. In Callon, M. (Ed.). The laws of the markets (Chap. 1, pp. 1 - 57). Blackwell: Oxford.

Callon, M. (1986) Some elements of a sociology of translation: domestication of the scallops and the fishermen of St Brieuc Bay. In Law, J (Ed.). Action and belief: a new sociology of knowledge? (Chap. 7, pp. 196 - 223). London: Routledge.

Camillis, P. K. \& Antonello, C. S. (2016) Da translação para o enactar: contribuições da Teoria AtorRede para a abordagem processual. Cadernos EBAPE, 14 (1), 61 - 82.

Cohen, E. \& Cohen, S. (2012) Current sociological theories and issues in tourism. Annals of Tourism Research, 39 (1), $2177-2202$.

Collins, H. \& Yearley, S. (1992) Epistemological chicken. Pickering, A. (Ed.) Science as Practice and Culture (Chap. 4). Chicago: University of Chicago Press.

Diekmann, A. \& Hannam, K. (2012) Touristic mobilities in India's slum spaces. Annals of Tourism Research, 39 (3), 1315 - 1336.

Duarte, R. \& Teles, A. (2017) Seguindo os caminhos do turismo por meio da teoria do ator-rede. Seminário da Associação Nacional de Pesquisa e Pós-Graduação em Turismo, São Paulo, Brasil. Recuperado de https://www.anptur.org.br/anais/anais/files/14/879.pdf

Duim, R. van der. (2007) Tourismscapes: an actor-network perspective. Annals of Tourism Research, $34(1), 961-976$.

Duim, R. van der \& Caalders. (2008) Tourism chains and pro-poor tourism development. Current Issues of Tourism, 11 (2), $109-125$.

Duim, R. van der \& Marwijk, R. (2006) The implementation of the environmental management system for dutch tour operators. Journal of Sustainable Tourism, 14 (5), 449 - 472.

Duim, R. van der, Ren, C., \& Jóhannesson, G. (2017) ANT: a decade of interfering with tourism. Annals of Tourism Research, 64, 139 - 149.

Edensor, T. (2001) Performing tourism, staging tourism: (re)producing tourist space and practice. Tourist Studies, 1(1), $59-81$.

Elder-Vass, D. (2008) Searching for realism, structure and agency in Actor Network Theory. The Bristish Journal of Sociology, 59(3), 455 - 473.

Emerich, A. M. (2017) Estudo bibliométrico no Portal CAPES: termos e conceitos de educação em museu (Dissertação de mestrado). Preservação de Acervos de Ciência e Tecnologia, Museu de Astronomia e Ciências Afins, Rio de Janeiro, RJ, Brasil.

Fullagar, S. (2001) Encountering otherness: embodies affect in Alphonso Lingis' travel writing. Tourist Studies, 1 (2), 171 - 183.

Franklin, A. (2004) Tourism as an ordering: toward a new ontology of tourism. Tourist Studies, 4(3), $277-301$.

Franklin, A. (2007) The problem with tourism theory. In Ateljevic, I.; Pritchard, A. \& Morgan, N. (Ed.) The critical turn in tourism studies (Chap. 9, pp. 131 - 148). Oxford: Elsevier. 
Gaitán, S. B. M. (2014) Los ensambladores y el entramado turístico: un aporte desde la investigación cualitativa. Anais Brasileiros de Estudos Turísticos, 4(2), 8 - 18.

Gaitán, S. B. M. (2012) Auténticamente tafinisto? Hurgando en el campo para decifrar la construcción de productos turísticos. Anais Brasileiros de Estudos Turísticos. 2(2), 20 - 32.

Harwood, S. \& El-Manstrly, D. (2012) The performativity turn in tourism. University of Edinburgh Business School Working Paper Series, 12 (5).

Hummels, J. \& Duim, R. van der. SNV's modes of ordering: organizing tourism as development practice. Tourism Management, 57, 312 - 322.

Ingold, T. (2008) Tres en uno: Cómo disolver las distinciones entre cuerpo, mente y cultura. In Criado, T. S. (Ed.). Tecnogénesis, v. 2. Madrid: AIBR.

Jacso, P. (2005) As we may search: comparison of major features of the Web of Science, Scopus and Google Scholar citation-based and citation-enhance databases. Current Science, 89 (9), 1537 $-1547$.

Jamal, T. \& Camargo, B. (2014) Sustainable tourism, justice and ethic of care: towrad the Just Destination. Journal of Sustainable Tourism, 22(1), 37 - 41.

Jóhannesson, G. (2005) Tourism translations: actor-network theory and tourism research. Tourist Studies, 5(2), $133-150$.

Lamont, M. (2013) Authentication in sports tourism. Annals of Tourism Research, 45, 1 - 17.

Larsen, J. \& Urry, J. (2011) The tourist gaze 3.0. London: SAGE publication.

Latour, B. (2015) Faturas/ Fracturas: da noção de rede à de vínculo. ILHA. 17(2), 123 - 146.

Latour, B. (1994) Jamais fomos modernos. Rio de Janeiro: Ed. 34.

Latour, B. (2013) Investigácion sobre los modos de existência. Buenos Aires: Paidós.

Latour, B. (1999) On recalling ANT. In Law, J. \& Hassard, J. Actor Network theory and after (Chap.1, pp. 15 - 25). Oxford: Blackwell publishers.

Latour, B. (2012) Reagregando o social: uma introdução à teoria ator-rede. Bauru: EDUSC.

Latour, B. \& Woolgar, S. (1997) A vida de laboratório. Rio de Janeiro: Relume Dumará.

Law, J. (2007, 25 th April). Actor Network Theory and Material Semiotics. Recuperado de: <http// www.heterogeneities.net/publications/Law2007ANTandMaterialSemiotcs.pdf>

Law, J. (2004) After method: mess in social science research. Londres e Nova York: Routledge.

Law, J. (1992) Notes on the Theory of the Actor-Network: ordering, strategy and heterogeneity. Systems Practice, 5 (1), 379 - 393.

Law, J. (1986) On the methods of long distance control. In Law, J. (Ed.) Power, action and belief. (Chap. 11, pp. 234 - 264). Londres e Nova York: Routledge.

Law, J. (2003) Ordering and obduracy. Recuperado de: <http://www.lancaster.ac.uk/fass/ resources/ sociology-online-papers/papers/law-ordering-and-obduracy.pdf $>$. 
Law, J. \& Mol, A. (1995) Notes on materiality and sociality. The Sociological Review, 43 (1), pp. $274-294$.

Lee, N. \& Brown, S. (1994) Otherness and the actor network. American Behavioral Scientist, 37 (6), pp. $772-790$.

Lugosi, P. (2016) Socio-technological authentication. Annals of Tourism Research, 58, 100 - 113.

MacCannell, D. (1973) Staged authenticity: arrangements of social space in tourist setting. American Journal of Sociology, 79(3), $589-603$.

Machado, L. de S. \& Macêdo, K. B. (2016) Análise bibliométrica dos estudos nacionais em clínicas psicodinâmica do trabalho. Revista Subjetividades, 16(1), 9 - 23.

Miller, D. (2005) Materiality: an introduction. In Miller, D. (Ed.). Materiality. (Chap. 1, pp. 1 - 50). Durham: Duke University Press Books, 2005.

Mkono, M. (2013) Using net-based ethnography (netnography) to understand the staging and marketing of 'arthentic african' dining experiences to tourists at Victoria Falls. Journal of Hospitality \& Tourism Research, 37(2), $184-198$.

Mol, A. (2010) Actor-Network Theory: sensitive terms and enduring tensions. Kölner Zeitscheift für Soziologie und Sozialpsychologie, 50(1), $253-269$.

Mol, A. (2002) The body multiple. Durham: Duke University Press.

Mordue, T. (2009) Angling in modernity. Current Issues in Tourism, 12(5), 529 - 552.

Mordue, T. (2005) Tourism, performance and social exclusion in "Olde York". Annals of Tourism Research, 32(1), 179-198.

Panosso Netto, A. \& Nechar, M. C. (2014) Epistemologia do turismo: escolas teóricas e proposta crítica. Revista Brasileira de Pesquisa em Turismo, 8(1), 120-144.

Panosso Netto, A., Noguero, F. T., \& Jãger, M. (2011) Por uma visão crítica nos estudos turísticos. Turismo em Análise. 22(3), 539 - 560.

Picken, F. (2010) Tourism, design and controversy: calling on non-humans to explain ourselves. Tourist Studies, 10(3), $245-263$.

Porter, A. (2007) How tech mining can enhance R\&D management. Research Technology Management, 50(2), 15 - 20.

Pritchard, A. (1969) Statistical bibliography or bibliometrics? Journal of Documentation, 25(4), 348 -349 .

Ren, C. (2011) Non-human agency, radical ontology and tourism realities. Annals of Tourism Research, 38(3), 858 - 881.

Ren, C., Pritchard, A., \& Morgan, N. (2010) Constructing tourism research: a critical inquiry. Annals of Tourism Research, 37(1), 885 - 904.

Salvatti, L., Mavrakis, A., Serra, P. \& Carlucci, M. (2015) Lost in translation, found in entropy. Applied Geography, 60(1), pp. 107 - 119. 
Serres, M. (1996) Diálogo sobre a ciência, a cultura e o tempo. Lisboa: Wook.

Tiberghien, G., Bremner, H., \& Milne, S. (2017) Performance and visitors' perception of authenticity in eco-cultural tourism. Tourism Geographies, 19(2), 287 - 300.

Tribe, J. (2010) Tribes, territories and network in tourism academy. Annals of Tourism Research, $37(1), 7-33$.

Urry, J. (1996) O olhar do turista. São Paulo: Studio Nobel: SESC.

Walsham, G. (1997) Actor-network and IS research: current status and future prospects. In Lee, A. B.; Liebenau, J.; Degross, J. (Ed.). Information systems and qualitative research. (Chap. 22, pp. 466 - 480). London: Chapman and Hall.

Whittle, A. \& Spicer, A. (2008) Is actor-network theory critique? Organization Studies, 29(4), 611 629.

Zhu, Y. (2012) Performing heritage: rethinking authenticity in tourism. Annals of Tourism Research, 39(3), $1495-1513$.

Contribuição de cada autor para elaboração

Anna Karenina Chaves Delgado: Redação do Artigo

Jackeline Amantino de Andrade: Orientação 